\title{
Inclusive Leisure Activities: Necessary Skills for Professionals. An Exploratory Study
}

\author{
Ingo K. Bosse, Ines Westermann \\ TU Dortmund University, Germany
}

\begin{abstract}
Recreation and leisure activities play a vital role in all our lives, but there is a considerable lack of research concerning the necessary knowledge regarding how to organize them appropriately for persons with disabilities. The present study seeks to find out what professional providers need to know in order to organize such activities. For this purpose, twelve face-to-face interviews and a focus-group discussion were carried out. The designated experts of course included some with disabilities. The results were evaluated according to certain core categories, devised using a combination of deductively and inductively oriented methods. The findings are indicative of the significant challenges involved in leading an active and varied life outside specialized institutions. It is important for professionals to be knowledgeable about the societal background of the concept of inclusion. Besides this knowledge, which concerns the issue of raising awareness, professionals need to be well informed about the most common disabilities and their effects, and also be aware of environmental factors.
\end{abstract}

\section{Introduction}

The focus of the current discourse on inclusion is on the school system. Inclusion in the leisure sector has been given less attention. Although the Convention on the Rights of Persons with Disabilities (CRPD) of the United Nations (UN) focuses on a human rights-based policy and its practical organization, "rights relating to sport, recreation, leisure and play remain on the edge of human rights practice" [12]. During the first review in Germany that examined the current implementation of the CRPD, it became clear that inclusive leisure time takes place on the periphery of the political discourse. The Federal Republic was certified as having extensive deficits in numerous participation areas. For Article 30, which is dedicated to participation in cultural life, recreation, leisure and sport, the UN committee made only one suggestion for its implementation: to sign the international agreement on copyright exceptions for persons with visual impairments [20].

In addition to considering accessibility to cultural activities, performances and services, Article 30 focuses on the promotion of creative, artistic and intellectual potential of persons with disabilities and their specific cultural identity. Paragraph 5 refers specifically to participation in recreation, leisure and sport activities. Appropriate measures should be taken with a view to enabling persons with disabilities to participate on an equal level with others in recreational, leisure and sporting activities [20]. The following research project is characterized by such an understanding of participation in leisure activities. The research project is about inclusive leisure activities, where the provider is responsible for the organization and content. Providers supply or organize the necessary offers of support. Inclusive leisure activities must be distinguished from leisure activities organized by persons with disabilities on their own behalf, for which they only need some assistance with transport or company. Inclusive leisure activities in culture, recreation, leisure time and sport are open to all children, adolescents and adults, disabled and non-disabled. It is still legitimate to create offers for specific target groups. But these are not regarded as inclusive.

The 13th German children and youth report, which is dedicated to the topic of inclusion, indicates the interface problems between child and youth welfare, disabled welfare and healthcare. The central problem here is the different service responsibility of child and youth welfare and social welfare in Germany. The different responsibilities of services are due to the distinction made between children and adolescents with and without disabilities, as well as that between the different types of disability.

Regardless of the current political discussion, more and more providers of leisure activities are starting to design their offers inclusively. Researchers are also taking an increasing interest in these issues [11, 20]. In contrast to the implementation of inclusion in the school system, the implementation of inclusion in leisure time can only occur on a voluntary basis. Next to informality, choice and timing, this corresponds to the action elements of self-determined leisure time and benefits the configuration of freedom of inclusive activities [17]. This sphere offers numerous possibilities for action to increase the inclusiveness of society, but overall inclusive leisure activities are not yet available. Nevertheless, the number of institutions that are trying to customize culture and leisure activities for everybody is increasing. Thus institutions often reach accessibility beyond the legal standards for accessibility $[2,3]$.

In contrast to currently discussed inclusive education, inclusive leisure activities are less 
regulated. This makes it easier to implement ideas for the configuration of inclusion. Leisure time can thus be seen as a think- tank of ideas for inclusion. The awareness of the need to design leisure activities inclusively is growing [20]. This results in an extensive need for action regarding the appropriate implementation of inclusion in leisure activities [13].

\section{Participation in leisure time: theoretical background}

Marx calls free time "disposable time", time that is free of work, during which the human being can evolve [15]. "It gives the opportunity for freedom of choice, conscious decision and self-determined social action. (...) In leisure time people can satisfy needs, like recreation, dissipation, communication, sociability, education, exercise, identity formation and self- realization which they miss out in other areas of life"'[1].

If leisure is seen as the complete range of time available, it can be divided into the categories of determined time, obligatory time and disposable time. Determined time consists of time that is used for involuntary tasks like work. Obligatory time describes time that is used for tasks with a specific purpose, such as sleeping, eating, doing the housework and shopping. The remaining free time is called disposable time. In the scale from determined time to disposable time, the use of time becomes more and more self-determined [17].

This classification applies to all people equally; the model expands slightly for persons with mental and complex impairments. Specific time for education (e.g. learning of daily-life activities), specific rest and sleep periods and possible care time need to be considered. These time categories cannot be clearly distinguished from one another. They are influenced by individual needs and circumstances as well as environmental factors [18].

This classification of time can be divided into four individual and social functions [17]. Recreation, compensation, education and contemplation can be seen as individual needs. These are easy to realize for persons with disabilities. Social functions concern the need to participate in the life of the community and is therefore more difficult to fulfill [14].

The International Classification of Functioning, Disability and Health (ICF) [21] defines participation as involvement in life situations. The success or failure of participation depends on contextual factors (environmental and personal factors). With regard to participation in leisure activities, these contextual factors can be seen as barriers or facilitators [11]. Taking into account that participation is a complex and multi-layered construct, the model of the ICF served as a basis for this study [4].

\section{Participation in leisure time: state of research}

Up to now, little evidence-based research has been carried out in Germany concerning leisure time of persons with disabilities. Furthermore, the available data is outdated, but still in accordance with international research, which mainly refers to persons with physical or with intellectual disabilities. The broad consensus is that "participation in leisure activities contributes to the physical, mental, and social health of individuals, families, and communities." [11]. It is also noted, that the kind of functional impairment as well as their extent and visibility are important as regards the possibilities of activity and participation in inclusive leisure time [8, 14]. International research is now focusing on optimizing social participation instead of just improving body functions and functional abilities [11]. In addition, recent studies refer to the following indicators that influence participation in leisure time:

\subsection{Personal factors: individual leisure behavior}

Leisure needs and interests of persons with disabilities are basically similar to those of other citizens. Canadian and Spanish results show that adolescents with physical impairments have the same interests as all others. However, research on their participation in organized leisure time shows that their activities have a lower diversity and intensity. Passive activities are used more often for recreation (as for example television) and social activities less often. At the same time, inclusive leisure activities are enjoyed very much $[8,11]$. The leisure behavior of all people is influenced by various factors. Age, gender, place of residence, socio-economic origin and social network or offers need to be considered. Additionally, in the case of adolescents the type of school, the extent and quality of personnel and material aid as well as the time factor is important. Studies that examine institutionalized leisureeducational holiday offers for adolescents with intellectual impairments point to the low educational value of the leisure habits and interests of this clientele [11].

In promoting the development of personal capacities for creating leisure activities, there is a risk of classifying activities in this group by their therapeutic aspects [6]. Horse-riding becomes hippotherapy, music becomes music therapy and so on. Persons with disabilities need, on average, more time for purpose-engaged activities, such as shopping, housework or work, so little time is left for leisure activities [1]. Furthermore, selfdetermination is limited because support and company is often necessary. This is the case 
especially when leisure habits and interests of persons with disabilities are not incisive. They are still more often on their own when involved in leisure activities. This tendency is mainly influenced by the severity of their impairments. Interviews with persons with disabilities clearly show that they are dissatisfied with the availability of suitable leisure activities. There is a desire for more autonomy, participation and, in particular, for inclusive leisure activities [1].

\subsection{Environmental factors at the material level}

The ICF (WHO 2001) defines participation as involvement in life situations, which succeeds or fails depending on contextual factors (such as environmental factors and personal factors). When it comes to participation in leisure time, these contextual factors can be seen as barriers or facilitators [11]. Leisure activities seem to be susceptible to various kinds of barriers and disadvantages, which are additionally affected by the severity and visibility of their impairment. Individual possibilities vary considerably and consequently limit both the freedom of choice and action.

The German Participation Report (Teilhabebericht) of the Federal Government shows that a self-determined arrangement of leisure time and participation in leisure offers is often still restricted or even impossible because leisure activities are often provided in places that are not fully accessible or usable. Furthermore, the offers are not sufficiently adapted to the needs of persons with disabilities. Missing or only limited information makes access even more difficult.

The costs of events and facilities as well as for carrying out hobbies plus the need for support and company are barriers to self-determined leisure activities [11, 1]. Markowetz outlines mobility and communication as well as inaccessible information about leisure activities essentially as barriers even more difficult to overcome than the architectural ones [13]. Another way of putting it, is to say that these barriers show just what contributes to a full and equal participation in leisure activities.

\subsection{Environmental factors at the level of professionals: awareness-raising and skills}

For equal participation in leisure time, a welcoming environment is just as important as accessibility [11]. For persons with disabilities, it is imperative to not just look for technical aid (for example in accessibility) but for a social-integrative solution (the dismantling of mental barriers or destigmatization) [13]. The Federal Youth Committee reveals the need to sensitize agencies and professionals with the focus on individual conveyor need and on social barriers. In practice, there exist more reservations than real problems [5]. The reservations and reluctance of professionals to adapt to special needs and demands continue to exist [1].

\subsection{Environmental factors at the institutional level: inclusion in the community}

According to article 23 of the UN Convention on the Rights of the Child, every child, and especially children with disabilities have the right to participate actively in the community [11]. International research findings make clear that leisure activities are suitable ways of promoting inclusion in communities: when experiencing belonging to a group or community, people become more aware of their individuality [8]. In this process, providers have the task of making places where leisure activities take place accessible [6].

This issue is being intensively discussed in Germany. The research focus here is particularly on child and youth work, as well as on children's and youth holidays $[7,20]$. This is due to the fact that in Germany there is currently an intensive discussion taking place on the interface problems between child and youth welfare on the one hand and disabled welfare and the health service on the other. Based on the livelihood approach, it seems obvious to create an offer that gives priority to the life situation of children and youth before those with disabilities. In the present research situation, where one can only refer to trends, it is noticeable that adolescents with disabilities mainly take part in holiday camps rather than in events or holidays provided by youth welfare and youth associations. An explanation for these findings is the fact that separation in school between the disabled and non-disabled still exists as well as longer journey times and therapy sessions in the afternoon. This accounts for less contact opportunities and friendships between children with and without disabilities [5, 20]. Overall, it can be recognized that some findings referring to the participation of persons with disabilities in inclusive leisure activities are given, but that there are hardly any findings concerning demands made on the providers. Some suggestions are made by King et al. [8] who draw attention to the importance of consultation for parents, and the need for them to encourage their children and support them to take part in activities for which they feel a passion. Providers should pay special attention as to which activities children enjoy and which kind of activities are relevant and of use to them.

Besides these Canadian researchers, their Irish colleagues Buttimer and Tierney point to a pressing need for further research into the provision of inclusive leisure activities. There is a real need for further research, particularly into how far barriers 
prevent full participation in leisure activities needed to be undertaken in order to facilitate full inclusion. The importance of the development and maintenance of friendships and the role of parents, service providers and leisure providers in enabling adolescents with intellectual disability to achieve their full potential in the area of leisure and recreation also require further investigation. "Service providers should take a leading role in promoting inclusive practices and programmes to ensure that individuals with [...] disabilit[ies] can use generic local leisure resources and activities with nondisabled peers." [6]. This statement points out the importance of leisure providers and the existing barriers that still prevent full participation. However, the introductory statements concerning providers of organized leisure time are merely additional findings. The studies cited first of all examined the leisure habits and behavior of persons with disabilities. Overall, the available data on leisure time is inadequate and of limited use, particularly regarding participation opportunities and limits of organized offers by free and public providers. It is not possible to make evidence-based statements about who uses organized offers inclusively and how it works in practice [1].

\section{An exploratory interview study on the creation of inclusive leisure time}

The purpose of the exploratory study presented here was to collect qualitative data on didactic requirements for professionals in order to create inclusive leisure activities for children, adolescents and adults. Based on the state of research, the central research question was formulated as follows: how can people exercise their human right to leisure time like persons without disabilities? With regard to this question, the following aspects were investigated: what support is needed to ensure that persons with disabilities have access to recreational, leisure and culture activities and their providers? What is essential regarding the accessibility of leisure sites? The aim of this study is to acquire basic knowledge that is important for a wide range of leisure sites, such as offers of open as well as of faith-group based child and youth work, of nature conservation organizations and of cultural facilities as well as towns and local authorities.

Another aim consisted in developing training for providers of inclusive leisure time and holiday offers on the basis of the knowledge generated, and in testing, evaluating and setting up such training permanently.

\subsection{Methodology}

In order to get a triangulation, expert interviews and a focus group discussion were used as research methods. The aim of this triangulation was to review the results reciprocally. Twelve face-to-face interviews and a focus-group discussion, which included professionals with a wide range of experience, were carried out in 2014. The experts designated naturally included some with disabilities. The aim of the interviews was to find out what kind of knowledge is necessary in order to arrange inclusive leisure time. For this reason, there were experienced providers of inclusive services as well as less experienced providers among those questioned. The participants work for a wide range of organizations, e.g. the Scout Movement, a selfadvocacy organization (Lebenshilfe), a Protestant youth association as well as researchers and a representative of people with disabilities. Based on the research interest in what factors facilitate participation in cultural life, recreation, leisure time and sports and what knowledge is necessary, institutions with a range of experience in inclusive leisure time were interviewed.

In fall 2014, an interactive exchange was reached based on group discussion. In this group discussion there were six participants from five institutions. The aim of the group discussion was to get to know the wishes and thoughts of the target group within the framework of a dynamic discussion. What was relevant for the composition of the group was the dispersion over the leisure area and the participant's professional origins. Participants were experts in open child and youth welfare, inclusive media education, inclusive leisure time, urban holiday games as well as of an inclusive sports club. In order to be able to compare the results of both kinds of evaluation, identical guidance notes were used. Visualized conversation impulses were used additionally during the group discussion to encourage a result-open exchange.

A preliminary study ensured the quality of the guidance notes for the interviewers. It contained a variety of questions: the spread of inclusive leisure offers, difficulties as well as possibilities of support in the process of making their offers inclusive for employees of children and youth welfare and disabled welfare or the youth associations, accessibility of the target group, personnel equipment and skills, meaning accessibility, the significance of types of disability as well as financial and legal aspects.

As an evaluation method, the contentsummarizing analysis by Mayring was chosen. The aim of this analysis is to reduce the material in such a way that the essential contents are preserved, to create a clear body by abstraction that is still an effigy of the base material. Beside the quality 
criterion, the focus was on creation and allocation of categories [9]. In preparation for the analysis, the audio recordings of the interviews and of the group discussion were transcribed. The second stage was to work on a content-summarizing analysis with MAXQDA software [10]. The results were evaluated according to certain core categories, which originated in desk-based research and were used to create the interview guidelines, and also by using an inductively oriented procedure. The principal concept behind the deductively-created categories was again the ICF of the WHO.

\subsection{Results of the generalizing analysis}

In the following generalizing analysis, the results of all interviews were compared with each other. In this step, commonalities and similar statements were identified and grouped together in order to reach first generalized findings. To prevent a generalization of different statements, distinctions were worked out, too. In consideration of the commonalities and differences, possible basic tendencies were determined. Every expert interview as well as the group discussion were summarized based on the following core categories.

The structure of categories resulting from the analysis of the interviews is largely consistent with the theoretical preliminary considerations. The category "awareness raising" and the "conception of the human being" had a higher value than expected. Engagement with the understanding of inclusion in institutions was an inductively derived category. Very nuanced statements were generated for this category.

B. "Nowadays everybody implements inclusion. Not too long ago I was at a conference. Everybody is supposed to implement it, but one does not have the knowledge. Many colleagues have no knowledge, but everyone knows a little from their own experience."

J. "It is a subject everyone has dealt with by now; every agency, every institution of youth welfare. A broader understanding of inclusion has become established, rather than speaking of inclusion just for children and adolescents with disabilities."

A great part of the expert interviews and the group discussion was concerned with the factors making for success at the level of agencies and facilities respectively. Factors for success were most frequently described as organizational and structural challenges.

G. "There are certain places where there is cooperation, because maybe there is a welfare facility for the disabled or a special school round the corner or a youth group leader himself has a child who has a disability.
There are some good examples, but this is not commonly the case. This refers particularly to the separating effects of the school system, which results in friendships not developing and youth work is based on this peer relationships"

The categories of "awareness raising" and the "conception of the human being" as well as accessibility turned out to be relevant in the ensuing training which was developed. Therefore, the results of the content-summarizing analysis of these two categories will be presented in greater detail.

4.2.1. Awareness-raising for the arrangement of inclusive leisure time. The allocation of statements to the category of "awareness-raising" was done based on Article 8: "awareness-raising" of the Convention on the Rights of Persons with Disabilities:

"(a) To raise awareness throughout society, including at the family level, regarding persons with disabilities, and to foster respect for the rights and dignity of persons with disabilities;

(b) To combat stereotypes, prejudices and harmful practices relating to persons with disabilities, including those based on sex and age, in all areas of life; with it, position, attitudes and the conception of the human being is considered, as well as measures which should be taken to cause changes." [19].

\subsubsection{Awareness on the organizational level.}

J. "It depends on the attitude. I have read the One-Point strategy once. We just offer one inclusive trip and then we are done with it. But inclusion is way more. Inclusion has to be fully implemented in the organization. Many people are not aware of this."

Organizations and associations should develop awareness as their social duty. Their social task is to adjust their offers towards inclusion and arrange them in a universal design. It requires the definition of individual aims and an obligation to make offers inclusive. Everyone is interested in making their offers accessible to everyone else; persons with disabilities are no longer excluded. Awarenessraising, without determining their self-image, takes place in associations to some extent. General Assemblies are necessary to raise the awareness of inclusion. The conception of the human being in the organization is essential, e.g. participation according to the Convention on the Rights of Persons with Disabilities or according to Christian understanding; participation regardless of religion, ethnic origin, impairments or sexual identity. A wider understanding of inclusion leads to greater participation. Children and youth work is open and 


\begin{tabular}{|c|c|c|c|}
\hline Category & Code & $\begin{array}{l}\text { Number } \\
\text { naming }\end{array}$ & $\%$ \\
\hline \multirow[t]{2}{*}{ Environ-mental factors } & & 92 & 15.3 \\
\hline & Community based & 32 & 5.3 \\
\hline \multirow[t]{5}{*}{ Accessibility } & & 60 & 10.0 \\
\hline & Products and technologies & 1 & 0.2 \\
\hline & Information and communication & 12 & 2.0 \\
\hline & Physical environment & 22 & 3.7 \\
\hline & Transport and mobility & 25 & 4.2 \\
\hline $\begin{array}{l}\text { Inclusive Leisure Time in } \\
\text { Institutions }\end{array}$ & & 249 & 40.4 \\
\hline \multirow[t]{5}{*}{ Agency } & Legal aspects & 8 & 1.3 \\
\hline & Financial aspects & 47 & 7.8 \\
\hline & Organization & 66 & 9.9 \\
\hline & Advertising & 22 & 3.7 \\
\hline & Networking & 37 & 6.1 \\
\hline \multirow[t]{3}{*}{ Professionals } & Qualification / personal resources & 50 & 8.4 \\
\hline & Personal assistance & 7 & 1.2 \\
\hline & Common statement employees & 12 & 2.0 \\
\hline \multirow[t]{4}{*}{ Social context } & & 89 & 15.0 \\
\hline & $\begin{array}{l}\text { Awareness raising and conception of } \\
\text { the human being }\end{array}$ & 60 & 10.0 \\
\hline & Understanding of inclusion & 20 & 3.5 \\
\hline & Research & 9 & 1.5 \\
\hline \multirow[t]{5}{*}{ Activities and Participation } & & 132 & 22.0 \\
\hline & Empowerment & 9 & 1.5 \\
\hline & Self- determined participation & 35 & 6.0 \\
\hline & Contact & 28 & 4.5 \\
\hline & Group interaction & 60 & 10.0 \\
\hline \multirow[t]{2}{*}{$\begin{array}{ll}\text { Body functions } & \text { and } \\
\text { structures }\end{array}$} & & 26 & 4.3 \\
\hline & Type of impairment & 26 & 4.3 \\
\hline
\end{tabular}

Figure 1. Topics by category: expert interviews and focus group

has a great knowledge of possibilities of participation and opening processes. But it is impossible to implement inclusive leisure time while saying 'please not in our museum'. Organizational development towards inclusion is an ongoing or enduring process where content and value need to be scrutinized, reflected on and discussed repeatedly. Inclusive leisure activities require a great deal of planning; the interaction with disabilities is often tense. Best practice examples can embolden organizations to create inclusive leisure activities. Within inclusive leisure offers, it is still common to think from the perspective of persons without disabilities.

4.2.3. Effective campaigns. In awareness campaigns, backgrounds and aims need to be described; patronage demonstrates the political dimension of inclusion. The focus of such annual actions should be on understanding disability and interacting with it. Single actions can establish acceptance and diminish fears. An explicit political will supports inclusive advancements. Naturally, media reports of inclusive leisure activities would raise awareness in society and outstanding successful engagements should be acknowledged where a winwin situation for providers could be achieved.

4.2.4. Attitudes of employees and participants. Professionals with an inclusive understanding of their professions can act as multipliers for knowledge. At the same time, all employees should consider their own views of diversity and their way of interacting with it. Dealing with attitudes of professionals and employees should draw on available resources.

Another good place to start is dealing with managements' doubts regarding the successful implementation of inclusion in companies and organizations. Many people already have positive attitudes but worries still exist about both the lack of skills and inclusion, in particular regarding people with an intellectual disability. The will to change is 
the first important step. While trying out changes, it is necessary to explain the approach and provide a specific list. Openness and acceptance is essential, just as much as the appreciation of a circle of friends. As well as combating doubts on part of the management, it is also a good place to start working on the doubts of other participants and employees. It is necessary to combat stereotypes and prejudices by not reinforcing stigmas, treating each other as equals and recognizing the needs of others. If adolescents gain experience in volunteer work, the fears of contact can be reduced and communication encouraged. Experts plead for training because they are aware of the concern that organizations have that employees who are not sufficiently prepared will not be able to handle the situation.

\subsubsection{Training}

L. "We want to provide training to reduce insecurity in the future. First of all, it is important to show openness and acceptance to all people".

Training should reverse misapprehensions and prejudices about inclusion and take away fears. Two central aspects that were examined during the interviews were accessibility and knowledge about disabilities. The knowledge provided should be usable in all kinds of leisure time (holiday trips, child and youth facilities and group interactions). It is important to note that inclusion does not automatically mean additional expense. Training should aim at a sensitization of the support and participation of persons with disabilities while not taking on a special status. Up to now, the achievements and deficits of persons with disabilities have been particularly emphasized. But special capabilities as well as special needs should be recognized. Employees should be given methods that encourage trying things out. Children should be seen as experts in their own right as concerns their own experience. Training should encourage the establishment of ongoing projects. Some suggestions could be inclusive games in easy-tounderstand language, sitting in on groups and methods of acquiring sensual experiences. Additionally, the group discussion illustrates the importance of being able to visit places independently where intimacy is required.

\subsubsection{Accessibility of inclusive leisure activities.} The category accessibility was generated based on Article 9 of the CRPD. Based on the understanding of accessibility in the German Act on Equal Opportunities for Disabled Persons (Behindertengleichstellungsgesetz) this category was differentiated into physical environment, transport and mobility, information and communication and products and technologies.

Generally, organizing travel and accommodation can be seen as having to make a great logistical effort with accompanying different kinds of barriers. Most statements made were with regard to transport and mobility. Difficulties with the German railway (Deutsche Bahn) were described in detail by all experts, but especially within the group discussion. Difficulties concern offers and information for persons with disabilities, as well as a lack of knowledge regarding the disability card. Another common fault is missing or defective ramps and lifts, as it is degrading and frightening, especially for children, to have to use the goods lift. The necessity of having to register in advance for every trip is experienced as degrading. The use of a tour bus was described as accessible, in contrast to public buses, which sometimes do not open the door.

Another barrier is the different daily routine of adolescents with disabilities, especially those who have long distances to travel and lack transport links. Parents can't miss work in order to help their disabled children to travel. Mobility training to reduce dependence were described as one approach to a solution. Further barriers to participating in inclusive leisure activities are financial, lack of a car, poor connections and over- stretched transport services.

G.D. "Just to be able to get into [a building]

does not mean it is inclusive. If you are inside and are able to participate, that is accessibility. That is my opinion.”. “(...)

'You cannot do that. You cannot ask a guest

if he could take someone to the toilet.' I say:

'Why not? Is he supposed to wet his pants?

What is the problem here?"'

This statement from the group discussion reveals that toilets are not always usable for persons with disabilities. This is a huge barrier for participation. Sliding doors and emergency buttons are required but not always present, even if sanitary facilities are provided for persons with disabilities. The duty to install a fully accessible toilet only applies to refurbishment projects. Differences regarding physical barriers exist between public or urban and private spaces. For example, information regarding accessibility is not always available; it is only on the internet. Physical accessibility is worthless without possibilities to participate. To create inclusive leisure activities, it is necessary to consider the adaptability of furniture, universal design, lighting working according to skills and preferences and arrangements for extra time.

Comments regarding information and communication can be summarized in the statement that digital accessibility is individual. Plain language is important to understand information on the internet or in brochures. To ease orientation at 
events, structured information and symbols are important.

In order to address participants with learning difficulties, easy communication is necessary. Furthermore, sign language and Alternative and Augmentative Communication should be used, if need be. Regarding the financial aspects of accessibility, the statements examined differ. On the one hand, economic interests should not be considered when regarding accessibility; on the other hand, accessibility should also pay off.

\section{Conclusion}

The aim of this study was to investigate what support is needed to ensure that persons with disabilities can participate in recreational, tourism, leisure and sporting activities. It examined the requirements towards providers of such activities and what professional training should involve. Based on the approach of triangulation, twelve face-to-face interviews and a focus-group discussion, which included professionals with a wide range of experience, were carried out. The experts designated naturally included some with disabilities. Among those questioned were experienced providers of inclusive services, as well as less experienced providers. They work for a wide range of organizations, for example ranging from the Scout Movement to nature conservation institutions. All are interested in making their services accessible to everyone. On the basis of the transcriptions of the interviews, a content-summarizing analysis was carried out.

The results were evaluated according to certain core categories, which originated in desk-based research and were used to create the interview guidelines, and also by using an inductively oriented procedure.

The findings are indicative of the significant challenges involved in leading an active and varied life outside the environments of specialized institutions and the home. It is important for professionals to be knowledgeable about the societal background of the concept of inclusion and to understand what it means to be a human being. They have to consider their own understanding of inclusion, self-determination and empowerment. Besides this knowledge, which concerns the raising of awareness, people who work in this field should acquire skills to deal with the most common disabilities and their effects for participation. They should also be aware of environmental factors such as accessibility (e.g. information, mobility and products). Furthermore, the study was able to identify specific challenges of a financial and legal nature, and a wide range of social, institutional and personal needs.
Training programs based on these standards were developed and carried out with trainers with and without disabilities. They are still taking place and are being scientifically monitored. A final remark is that the overall results, besides having established standards for training programs of the highest quality, show how inclusive recreational, tourism, leisure and sporting activities can promote empowerment.

Among the persons interviewed were scientific experts as well as experts with a practical background. For further research, it would be enlightening to ask the users of inclusive leisure activities themselves. The results do not allow conclusions about engagement and developmental benefits. It would be useful to develop a self-report measure of children's perceptions of competencyrelated, social, and psychological benefits of engagement in structured leisure and recreation activities [8].

Furthermore, the political problem regarding the different service responsibilities of child and youth welfare and social welfare in Germany has to be solved. Different responsibilities of the services are due to the distinction made between children and adolescents with and without disabilities, as well as to the distinction between the different types of disability. The proposal of the Federal Government to merge all minors, regardless of disability in Child and Youth Welfare would eliminate these interface problems. In the current coalition agreement the Federal Government made it clear that progress towards aid for development and participation is conceivable. However, concrete plans have not yet been reported [16].

Due to the fact that youth welfare as well as youth-related politics are generally led by the principles of equal opportunities and participation for everyone, youth work is especially important and inspiring for inclusive processes [3].

\section{Acknowledgements}

We would like to thank all the experts who participated in this for their insights into their work and organizations as well as all colleagues for their contributions to the training. We also thank Mona Koers for the transcription of the interviews and her contribution to the development of our coding system.

\section{References}

[1]BMAS - Bundesministerium für Arbeit und Soziales (Ed). Teilhabebericht der Bundesregierung über die Lebenslagen von Menschen mit Beeinträchtigungen, 2013, BMAS, Bonn, 2013. 
[2]Bosse, I. „Inklusive Schulkinowochen NRW.“, in: Schuppener, S., Bernhardt, N., Hauser, M. and Poppe, F. (eds.). Inklusion und Chancengleichheit. Diversity im Spiegel von Bildung und Didaktik, Klinkhardt, Bad Heilbrunn., 2014, pp. 320-325.

[3]Brockhorst, H. „Orientierungen für eine inklusive Praxis Kultureller Bildung“, in: Fuchs, M., Taube, G., Braun and T., Zacharias, W., (eds): Kulturelle Bildung für alle! Analysen, Standpunkte, Konzepte aus 33 Jahren Engagement für kulturelle Teilhabe, kopaed, Munich, 2008, pp.

[4]Bult, M.K., Verschuren, O., Jongmans, M.J., Lindeman, E. and Ketelar, M. "What influences participation in leisure activities of children and youth with physicla disabilities? A systematic review." Research in Developmental Disabilities, 32, 2011, pp. 1521-1529.

[5]Bundesjugendkuratorium. Inklusion: Eine Herausforderung auch für die KinderundJugendhilfe: Stellungnahme des Bundesjugenkuratoriums, Deutsches Jugendinstitut, Munich, 2012.

[6]Buttimer, J. and Tierney, E., "Patterns of leisure participation among adolescents with a mild intellectual disability", Journal of intellectual disabilities, 9, 2005, pp. 25-42.

[7]Dubiski, J. and Platte, A. "Im gemeinsamen Leben entsteht Normalität" - Inklusion und non-formale Bildung am Beispiel des Kinder und Jugendreisens, in C. Dorrance, C. and Dannenbeck, C. (eds.), Doing inclusion. Inklusion in einer nichtinklusiven Gesellschaft, Klinkhardt, Bad Heilbrunn, 2013, pp. 168-177.

[8]King, G., Petrenchik, T., de Witt, D., McDougall, J., Hurley, P., and Law, M., "Out-of-school time activity participation of children with physical disabilities. A cluster analysis." Child: Care, Health and Development, 36, 2010, pp. 726-746.

[9]Kuckartz, U., Qualitative Inhaltsanalyse. Methoden, Praxis, Computerunterstützung. Beltz Juventa, Weinheim and Basel, 2010.

[10]Kuckartz, U., Einführung in die computergestützte Analyse qualitativer Daten. Verlag für Sozialwissenschaften, Stuttgart, 2014.

[11]Longo, E., Badia, M., and Orgaz, B. M., "Patterns and predictors of participation in leisure activities outside of school in children and adolescents with Cerebral Palsy", Research in developmental disabilities, 34(1), 2013, pp. 266-275.

[12]Lord, J.E. and Stein, M.A., "Social Rights and the Relational Value of the Rights to Participtate in Sport, Recreation and Play", Faculty Publications. Paper 108; http://scholarship.law.wm.edu/facpubs/108 (26 May 2015).

[13]Markowetz, R. „Freizeit inklusive: Aspekte des Gelingens integrationspädagogischer Arbeit im Lebensbereich Freizeit", in Eberwein, H. (ed.), Integration konkret. Begründung, didaktische Konzepte, inklusive Praxis, Klinkhardt, Bad Heilbrunn, 2008, pp. 241-252.
[14]Markowetz, R. „Freizeit und Erwachsenenbildung für Menschen mit Lernschwierigkeiten", in Schwalb, H. and Theunissen, G. (eds.), Inklusion, Partizipation und Empowerment in der Behindertenarbeit. Best-PracticeBeispiele: Wohnen - Leben - Arbeit - Freizeit. Kohlhammer, Stuttgart, 2009, pp.176-188.

[15]Marx, K. Grundrisse, Penguin, London, 1857/58.

[16]Oehme, A., and Schröer, W. (2014). "Inklusion" - die Kinder- und Jugendhilfe ist gefragt ..." neue praxis, (2), 2014, pp.124-133.

[17]Opaschowski, W. (1990). Pädagogik und Didaktik in der Freizeit. Leske \& Budrich, Opladen.

[18]Theunissen, G. (2000) „Lebensbereich Freizeit - ein vergessenes Thema für Menschen, die als geistig schwerund mehrfachbehindert gelten", in Markowetz, R. and Cloerkes, G. (eds.), Freizeit im Leben behinderter Menschen. Theoretische Grundlagen und sozialintegrative Praxis; Universitätsverlag Winter, Heidelberg, pp. 137150.

[19]UN - United Nations: Convention on the Rights of Persons with Disabilities and Optional Protocol. New York, 2006.

[20]Voigts, G. „Partizipation von Kindern und Jugendlichen mit Behinderungen in der Kinder- und Jugendarbeit: Auf dem Weg zu einem inklusiven Gestaltungsprinzip“, Teilhabe, 52(1), 2013, pp. 18-25.

[21]WHO - World Health Organisation, International Classification of Functioning. Disability and Health, World Health Organisation, Geneva, 2001. 